\title{
AN EXPERIMENT IN SCHOOL AND STATE COOPERATION.
}

By Helen A. Loomis,

\section{Bowen High School, Chicago.}

At the request of one greatly interested in science in the high schools, this article is submitted. The purpose is to present a simple illustration of the assistance awaiting our public schools through the very willing cooperation of our state institutions and tusiness men. The experiment was worked out at the Bowen High School, Chicago, during this past year.

At the time of the Chicago Aquarium Society Exhibit, which attracted such crowds to the Art Institute, the State Fish Commission exhibited specimens of our food fishes. The zoology classes visited these exhibits, and enjoyed exceedingly the surprise of finding little fancy fishes as beautiful as birds. Unfortunately, our inland children's idea of fish is limited to bullheads, fifteencent goldfish, and pickled perch. The classes were given instruction on the characteristics of the living food fish, following advanced class work in the laboratory identification of preserved specimens. We then made bold enough to ask of Mr. C. B. Whitford, the State Fish Culturist, some of these specimens at the close of the exhibit, to complete our laboratory collection of twenty-five kinds. Through the kindness of Mr. Whitford and the courtesy of Mr. Meeteren, the State Commissioner, the specimens were obtained; but what is of more importance, these men became interested in our work.

The latter part of April, Mr. Whitford suggested the possibility of experimenting with a miniature hatchery in the laboratory. This tempting offer was promptly accepted, and the hatchery installed the first day of May. 'The state furnished the hatching jar and about 200,000 pike perch (walled-eyed pike) eggs. The jar was placed in the large goldfish tank with a trough connected at the spout. The eggs were then placed in the jar, and a current of water kept running through the pipe to the bottom, the surplus being carried off at the spout, which was covered by a bit of finemeshed screen. Thus the eggs were kept gently but constantly rolling. The observations of the changes in the condition of the eggs, and the temperature and pressure of the water, were recorded twice daily, and specimens removed to small bottles. The water pressure was regulated to about one gallon per minute, and the temperature averaged about $48^{\circ} \mathrm{F}$. Here should be acknowledged the very valuable assistance of our engineer, who saw that the water was never shut off, and of the night watchman, who kept 
the pressure regulated, as too violent rolling would have ruptured the yolk sacs.

Needless to say, interest in the hatchery spread through the student body, and several faculty members, who were daily visitors, offered substantial help about the minor details of the apparatus.

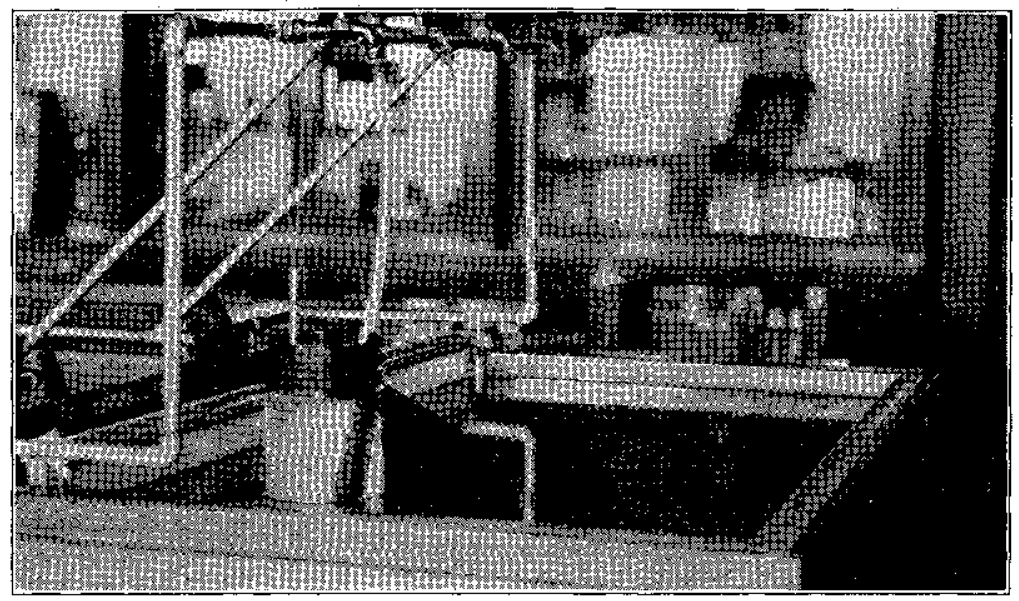

In ten days, we were rewarded by seeing some of the eggs "eyed out," and on the twelfth day, with the aid of the magnifying lens, the pulsations of the heart and the turning of the embryo in the eggs could be plainly observed. On the fourteenth day, the fish began to hatch, and the process, again under magnification, was most interesting. The egg would turn over and over violently and then the transparent little fellow would squirm out, tail first, and wriggle to the surface, greatly resembling mosquito larva. The screen was removed from the spout, and soon hundreds of the little fish could be seen swimming in the tank. Fish interest ran higher. In fact, the day was devoted to demonstrating fish hatching to the visitors. During the next few nights, an interesting observation was made by the watchman, who found at daybreak the hatching was so rapid as to make the jar appear filled with a mist.

Fully two-thirds of the eggs hatched; most of the remainder proved infertile, and a few were attacked by fungus. At the end of the week, when the yolk sac was absorbed, it was necessary to supply larger quarters to prevent cannibalism. The fish were siphoned out, and transported to Wolf Lake, and so returned to state waters. 
But even this does not include ail our benefits. During the time of the experiment, Mr. Whitford visited us, and, happening in on the Bird Club day, gave the members a splendid talk on game birds, as well as fish culture. A little account of our experiment was published in the paper, and came to the attention of the Aquarium Club, who invited the instructor to one of their meetings to tell about the little hatchery. This, too, bore fruit, for the members of the club became interested in our boys and girls, who are now to form an auxiliary chapter-to boost an aquarium for Chicago. Moreover, we are to have an aquarium of the beautiful little fishwhich we admired so much, but thought so unobtainable--the gift of these men.

\section{MOUNTING FOR PROTECTING THERMOELEMENTS.}

A mounting for protecting laboratory thermoelements from damage by contamination or by mechanical strains has been developed at the Bureau of Standards, Department of Commerce, in connection with investigations of the expansion of substances on heating. Protective mountings with convenient heads for attaching the leads to the millivolmeters that indicate the temperatures are common with industrial thermocouples; but the wires of the average couple to be seen in a physical or chemical laboratory are either entirely unprotected or else merely have portions adjacent to the junctions inserted in glass or porcelain tubes. The mounting regularly used in the expansion laboratory of the Bureau not only affords adequate protection to the thermoelement, but also adds greatly to the convenience of its use.

Scientific Paper, No. 276, entitled Protected Thermoelements, discusses this subject and persons interested may obtain copies, free of charge, upon request to the Bureau of Standards, Washington, D. C.

\section{GALVANOMETER DESIGN.}

Galvanometers are instruments for the detection or measurement of small electric currents or small voltages and are much used in variots kinds of electrical testing. The user of such an instrument is concerned with its sensitivity, either to current or to voltages, its period, etc.; that is, he is concerned 'with its performance or operation constants. These necessarily depend upon the intrinsic or construction constants, which in turn depend upon the size, shape, kind of material, etc., of. which the parts are nade.

The relations between these two sets of constants are of interest to both the uscr and the maker of galvanometers. They are, however, of more importance to the maker, since they may be made to serve as a basis for predetermining values for the intrinsic constants such as will give previously. selected or specitied values for the operation constants. In other words, the relations in question will tell him what values the construction constants must have in order that the galvanometer may meet definite performance specifications.

These matters are discussed and illustrated by concrete examples in a paper just published by the Bureau of Standards, Department of Commerce. Copies of the paper, Scientific Paper, No. 273, may be had on request addressed to the Director, Bureat of Standards, Washington, D. C. 